\title{
Electroporation-Mediated Plasmid DNA Vaccine Therapy
}

National Cancer Institute

\section{Source}

National Cancer Institute. Electroporation-Mediated Plasmid DNA Vaccine Therapy. NCI Thesaurus. Code C116536.

The use of an external electrical field to facilitate the transfer of a plasmid into a cell for the purpose of introducing genetically modified DNA and stimulating a immunological response. 